Journal of

Gastroenterology
GE Port J Gastroenterol 2021;28:297-300

DOI: $10.1159 / 000511529$
Received: May 20, 2020

Accepted: August 26, 2020

Published online: November 10, 2020

\title{
Percutaneous Transhepatic Cholangioscopy and Lithotripsy of Intrahepatic Stones
}

\author{
Maria João Madeira-Cardoso ${ }^{a}$ Nuno Almeida ${ }^{a}$ b Catarina Correia ${ }^{b}$ \\ Mariana Duque ${ }^{c}$ Alfredo Gil Agostinho ${ }^{d}$ Henrique Alexandrino ${ }^{a, c, e}$ \\ ${ }^{a}$ Faculty of Medicine, University of Coimbra, Coimbra, Portugal; ${ }^{b}$ Gastroenterology Department, Coimbra University \\ Hospital Centre, Coimbra, Portugal; ' Surgery Department, Coimbra University Hospital Centre, Coimbra, Portugal; \\ ${ }^{\mathrm{d}}$ Radiology Department, Coimbra University Hospital Centre, Coimbra, Portugal; ${ }^{\mathrm{e} C e n t r e ~ f o r ~ I n n o v a t i v e ~ B i o m e d i c i n e ~}$ \\ and Biotechnology, Coimbra, Portugal
}

\section{Keywords}

Lithotripsy - Percutaneous transhepatic cholangiography . Bilioenteric anastomotic strictures - Video cholangioscopy

\section{Colangioscopia percutânea transhepática e litotrípsia em litíase intra-hepática}

\section{Palavras chave}

Litotrípsia · Colangiografia percutânea transhepática . Estenoses de anastomoses bilio-entéricas .

Colangioscopia por vídeo

Stenosis of hepaticojejunostomy $(\mathrm{HJ})$ is a potentially serious postoperative complication after pancreaticoduodenectomy [1]. It causes biliary stasis leading to intrahepatic lithiasis and recurrent cholangitis.

We herein describe the case of a patient who underwent pancreaticoduodenectomy with Roux-en-Y recon- struction for an ampullary carcinoma 6 years earlier, developing late $\mathrm{HJ}$ stenosis. The first episode of cholangitis was 4 years after surgery. After a trial of percutaneous transhepatic dilation and drainage, the episodes of cholangitis recurred. A repeat magnetic resonance cholangiography showed a permeable $\mathrm{HJ}$ and development of intrahepatic lithiasis. An endoscopic retrograde cholangiopancreatography with double-balloon enteroscope [2] was unsuccessful due to a slight twisting of the Roux-en $\mathrm{Y}$ anastomosis, and the patient was placed with a percutaneous transanastomotic drain to prevent further episodes of cholangitis. Because of the proximity of the pancreatic anastomosis to the $\mathrm{HJ}$, a surgical approach was considered technically difficult and potentially hazardous. After multidisciplinary discussion, a percutaneous transhepatic cholangioscopy (PTC) [2] was decided. Under general anesthesia and systemic antibiotic therapy, a percutaneous $12 \mathrm{Fr}$ sheath was placed over a guidewire and the drain removed (Fig. 1a), allowing the introduction of a SpyGlass ${ }^{\mathrm{TM}}$ cholangioscope in the intrahepatic biliary tree (Fig. 1b) [2]. The procedure was performed karger@karger.com www.karger.com/pjg

Karger $\stackrel{\text { ' }}{5}$ BOPEN ACCESS
C 2020 Sociedade Portuguesa de Gastrenterologia Published by S. Karger AG, Basel

This article is licensed under the Creative Commons AttributionNonCommercial-NoDerivatives 4.0 International License (CC BYNC-ND) (http://www.karger.com/Services/OpenAccessLicense). Usage and distribution for commercial purposes as well as any distribution of modified material requires written permission.
Maria João Madeira-Cardoso

Surgery Department, Centro Hospitalar e Universitário de Coimbra Praceta R. Prof. Mota Pinto

PT-3004-561 Coimbra (Portugal)

mariajoao.madeiracardoso@gmail.com 
Fig. 1. a Initial patient setup in the angiography suite, with percutaneous biliary drain being replaced over a guidewire for a 12 Fr sheath. b The cholangioscope is being placed through the percutaneous sheath for the approach to the bile duct.
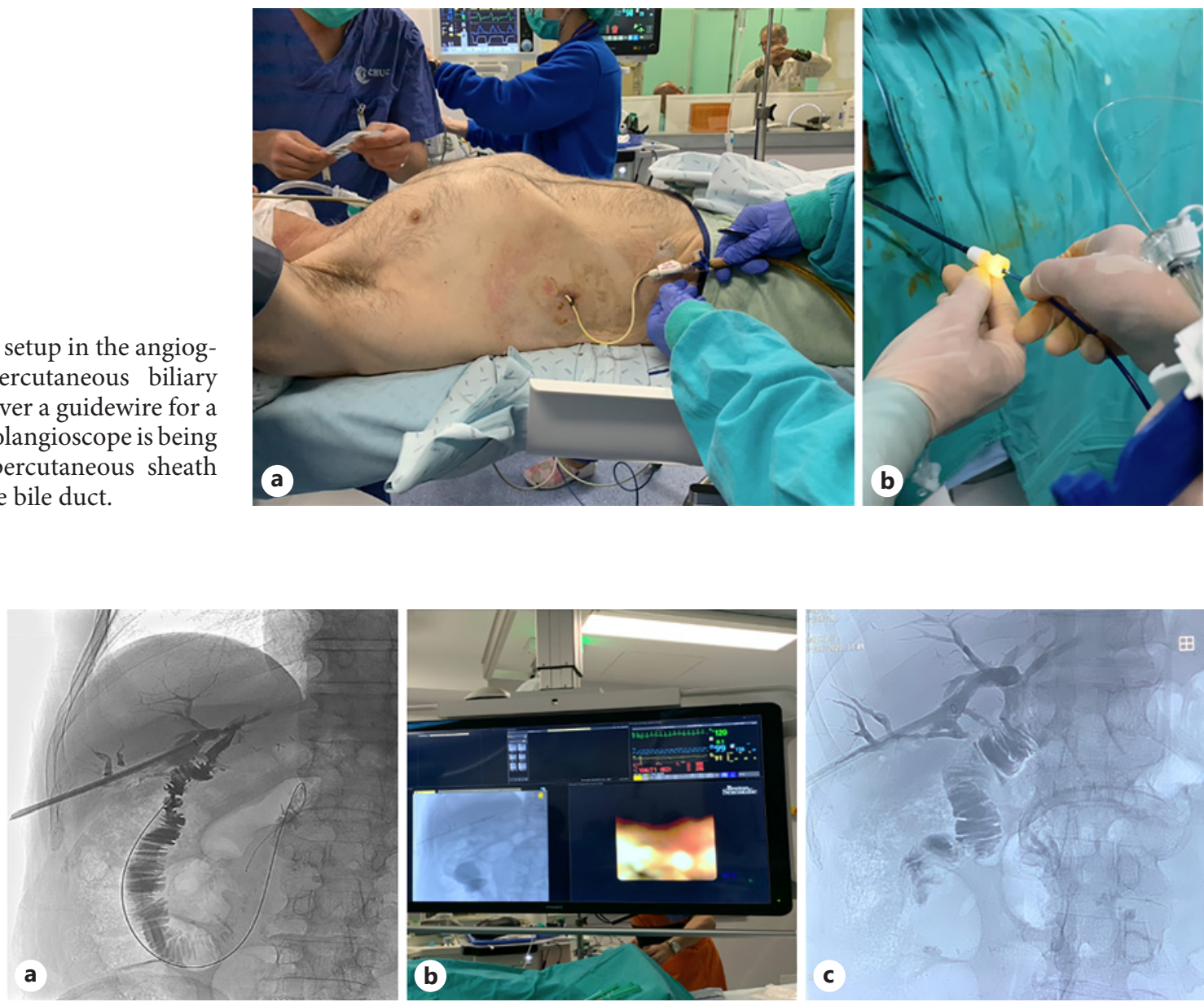

Fig. 2. a Initial cholangiography displaying the $12 \mathrm{Fr}$ sheath and multiple filling defects in the right posterior sectorial duct and no filling of the left hepatic duct, but with permeable anastomosis. b, c Simultaneous radiological and endoscopic percutaneous approach of the biliary tract reflecting the importance of a multidisciplinary team approach in cases such as these. The dual monitoring system allowed for the precise confirmation of the cholangioscope, enabling the clearance of the entire intrahepatic biliary tree.

with a dual-image system displaying the progression of the procedure with cholangiographic images alongside the cholangioscopic view, enabling the exact location of the cholangioscope inside the biliary tree, particularly of the most affected ducts (right posterior sector and left hepatic duct) (Fig. 2) [2]. During the procedure, the anastomosis was confirmed to be patent, and laser lithotripsy with Holmium Laser System ${ }^{\mathrm{TM}}(5 \mathrm{~Hz}$, minimum power increased as needed) [3, 4] (Fig. 3) and Dormia basket lithotomy [2] of intrahepatic stones were performed. Completion cholangiogram showed absence of major filling defects. However, since some debris remained even after copious lavage, a percutaneous transanastomotic drain was left in order to prevent cholangitis. This was removed 1 week after repeat cholangiography confirmed clearance of the intrahepatic ducts and a permeable HJ. Four months after the procedure, the patient is asymptomatic, with no clinical or biochemical signs of cholangitis or cholestasis.

This innovative, multidisciplinary approach ensured a clearance of the intrahepatic bile ducts without morbidity or the need for reoperation, making it a therapeutic option in cases of intrahepatic stones in patients with a previous Roux-en-Y reconstruction. It is a new technique with enormous potential to grow, but both worldwide experience and the literature on this topic are still scarce. Five cases of the PTC approach were reported with promising results; three of them were performed 
Fig. 3. Panel showing step-by-step approach of lithotomy and laser lithotripsy, with the laser being aimed (a), fired (b), and destroying a stone (c) into fragments (d).
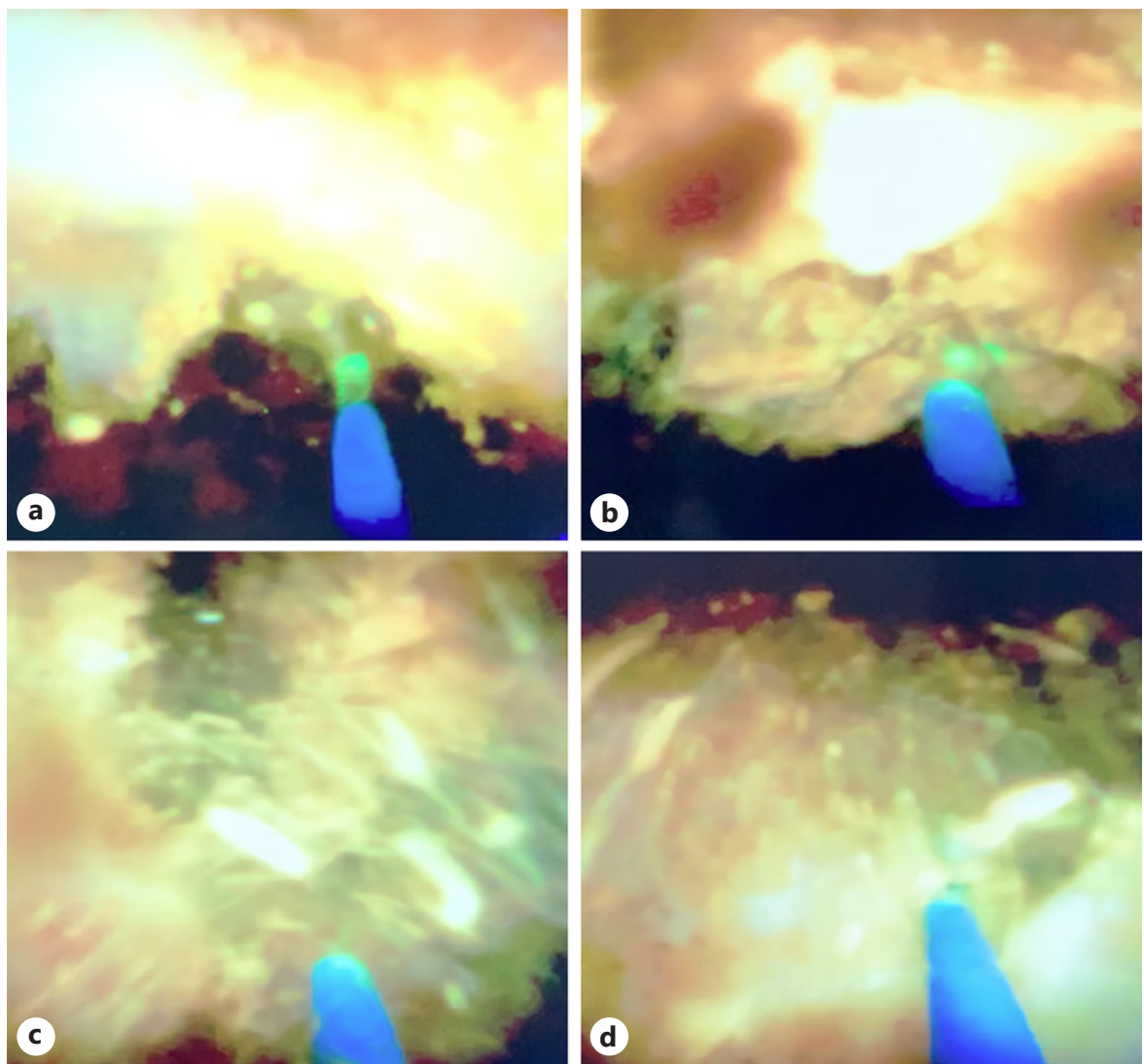

after Roux-en-Y HJ. In this series, just as in our case, PTC was performed given the unsuccess of the endoscopic approach - the first-line therapy for HJ dilatation [5]. PTC can offer both diagnostic and therapeutic options such as evaluation of biliary strictures, biopsies, lithotripsy, biliary stones removal, and also allow complete cleaning of the biliary ducts. Furthermore, as in the case we describe herein, in patients with a high lithiasis load, the endoscopic approach may not be feasible to achieve a complete intrahepatic clearance of stones. To the best of our knowledge, this is the first case using PTC for intrahepatic biliary lithiasis described in the Portuguese literature.

\section{Acknowledgement}

The authors wish to thank both Dr. Dário Gomes (Gastroenterology Department, Coimbra University Hospital Center) and Dr. Pedro Simões (Urology and Renal Transplant Department, Coimbra University Hospital Center) for contributing with their technical expertise in the clinical management of this case.

Percutaneous Transhepatic Cholangioscopy and Lithotripsy

\section{Statement of Ethics}

All procedures performed were in accordance with the ethical standards of the institutional and/or national research committee. The informed consent for the publication of the case and its corresponding images was given by the patient.

\section{Conflict of Interest Statement}

The authors have no conflicts of interest to declare.

Funding Sources

The authors received no financial support.

\section{Author Contributions}

The authors contributed equally to the writing of this paper. 


\section{References}

1 Mizukawa S, Tsutsumi K, Kato H, Muro S, Akimoto Y, Uchida D, et al. Endoscopic balloon dilatation for benign hepaticojejunostomy anastomotic stricture using short double-balloon enteroscopy in patients with a prior Whipple's procedure: a retrospective study. BMC Gastroenterol. 2018 Jan;18(1): 14.

2 Ahmed O, Mathevosian S, Arslan B. Biliary Interventions: Tools and Techniques of the Trade, Access, Cholangiography, Biopsy, Cholangioscopy, Cholangioplasty, Stenting,
Stone Extraction, and Brachytherapy. Semin Intervent Radiol. 2016 Dec;33(4):283-90.

3 Alabraba E, Travis S, Beckingham I. Percutaneous transhepatic cholangioscopy and lithotripsy in treating difficult biliary ductal stones: two case reports. World J Gastrointest Endosc. 2019 Apr;11(4):298-307.

4 Joseph L. McDevitt, MD, MBAa,b, Ravi N. Srinivasa, MD, FSIRa,c, Jacob J. Bundy, MD, MPHa, Anthony N. Hage, MDa, Jeffrey Forris Beecham Chick, MD, MPHa d. Interventional Radiology-Operated Choledocho-
scopic-Guided Radiofrequency Wire and Holmium Laser Ablations May Facilitate Treatment and Long-Term Patency of Benign Biliary Strictures. J Vasc Interv Radiol. 2020;30(5):766-9.

5 Tripathi N, Mardini H, Koirala N, Raissi D, Emhmed Ali SM, Frandah WM. Assessing the utility, findings, and outcomes of percutaneous transhepatic cholangioscopy with SpyglassTM Direct visualization system: a case series. Transl Gastroenterol Hepatol. 2020 Jan;5:12. 